\title{
Biopelículas de Aspergillus niger para la producción de celulasas: algunos aspectos estructurales y fisiológicos
}

\author{
Aspergillus niger biofilms for celulasas production: some structural and \\ physiological aspects
}

\author{
Gretty K. Villena y Marcel Gutiérrez-Correa *
}

Presentado: 24/06/2003

Aceptado: 18/07/2003

\section{Resumen}

Se evaluaron biopelículas de Aspergillus niger desarrolladas sobre tela de poliéster en dos aspectos fundamentales inherentes al crecimiento sobre superficies: la estructura y el comportamiento fisiológico específicamente relacionado con la producción de celulasas. La estructura de la biopelícula fue evaluada usando microfotografías de microscopía electrónica de barrido (SEM) desde el momento de la inoculación y adsorción de esporas hasta las 120 horas de crecimiento. Nuestros resultados demuestran que la formacion de la biopelícula ocurre en tres fases: la adhesión, la cual es fuertemente favorecida por la hidrofobicidad de las esporas de Aspergillus; la fase de crecimiento inicial y desarrollo, que se inicia con la germinación de la espora entre las 4 y 10 horas y continúa hasta las 24 horas cuando ya se percibe la colonización casi total de la superficie; y finalmente la fase de maduración, en la cual la densidad de biomasa se incrementa notablemente desde las 48 horas hasta las 120 horas; se observa, además en este momento una organización interna de canales, también reportada para biopelículas bacterianas, que aseguran el flujo interno de la biopelícula. Además, la actividad celulolítica de las biopelículas fue evaluada, siendo hasta $40 \%$ mayor que en los cultivos sin soporte de crecimiento (durante el transcurso de la fermentación), lográndose un incremento del $55 \%$ en la productividad. Estos resultados son concordantes con el comportamiento de la gran mayoría de microorganismos que crecen sobre superficies, los cuales muestran por lo general una mayor actividad metabólica resultante de una expresión genética diferencial. Este trabajo es un primer intento por establecer la estructura y fisiología de las biopelículas de hongos filamentosos de interés industrial en respuesta a la escasa información existente, en comparación con el minucioso y vasto estudio de biopelículas bacterianas y de levaduras patógenas.

Palabras clave: Aspergillus, biopelículas, celulasas, hongos filamentosos.

\begin{abstract}
Aspergillus niger biofilms developed on polyester cloth were evaluated considering two aspects related to the growth on surfaces: structure and physiological behavior focused on cellulase production. The biofilm structure was assessed by using electron scanning microphotographs from inoculation and adsorption to $120 \mathrm{~h}$ growth. The microphotographs show that biofilm formation can be divided into three phases: 1) Adhesion, which is strongly increased by Aspergillus spore hydrophobicity; 2) Initial growth and development phase from spore germination, that begins 4 to $10 \mathrm{~h}$ after inoculation and continues up to $24 \mathrm{~h}$ when almost all available surface has been colonized; 3) Maturation phase in which biomass density is highly increased from $48 \mathrm{~h}$ after inoculation until $120 \mathrm{~h}$ growth when an internal channel organization that assures medium flow through biofilm is clearly evident as it is frequently reported for bacterial biofilms. Biofilm cellulolytic enzyme activity and productivity were also evaluated, being up to $40 \%$ and $55 \%$, respectively, higher than that attained by freely suspended cultures. These results are in agreement with the behavior of most surface living microorganisms, which generally show a higher metabolic activity because of a differential gene expression. This work is a first attempt to understand the structure and physiology of industrial filamentous fungal biofilms as a response to the scarce available information in comparison with the vast and detailed information related to bacterial and pathogenic yeast biofilms.
\end{abstract}

Keywords. Aspergillus, biofilms, cellulase, filamentous fungii.

\footnotetext{
* Laboratorio de Micología y Biotecnología, Universidad Nacional Agraria La Molina,

Apartado 456 Lima 1, Perú. eMail Gretty Villena: gkvch@lamolina.edu.pe
} 


\section{Introducción}

Los hongos filamentosos son un grupo de interés industrial en la producción de enzimas. Aspergillus es un organismo ampliamente utilizado en la producción de una gran variedad de glucanasas con un espectro tal que puede lograrse la completa degradación de la celulosa. Las glucanasas son utilizadas en muchos procesos industriales, como bioblanqueo, panificación, extracción y clarificación de jugos, elaboración de alimento animal, industria textil, entre otras. Aspergillus muestra algunas ventajas para la producción industrial de enzimas: tiene un alto nivel de producción, presenta buenas propiedades para el cultivo, lo que posibilita la producción a gran escala, sus productos son generalmente considerados como GRAS (generally regarded as safe), lo que permite su aplicación en la industria de alimentos tanto para el hombre y animales (de Vries \& Visser, 2001).

Muchos hongos filamentosos están naturalmente adaptados al crecimiento sobre superficies. Los hongos requieren un contacto cercano con el sustrato debido a su nutrición heterótrofa, secreción de enzimas extracelulares, absorción de nutrientes a través de la pared celular y el crecimiento apical de sus hifas (Jones, 1994). Sin embargo, algunos sistemas de producción como la fermentación sumergida no considera estos importantes aspectos de su fisiología.

Algunos procesos utilizan hongos inmovilizados en distintos soportes sintéticos, y en el caso de Aspergillus se ha probado la inmovilización para la producción de ácidos orgánicos (Anderson, 1983). Sin embargo, esta técnica de cultivo está principalmente enfocada hacia la obtención de ventajas operativas del proceso, como son la reutilización de biomasa, la facilidad para la recuperación del producto y también una mayor productividad. Esta última característica resulta importante para considerar que la forma de crecimiento de estos microorganismos es determinante en su comportamiento fisiológico.
Los hongos que crecen sobre superficies constituyen biopelículas y como tales, muestran características fisiológicas particulares derivadas probablemente de una expresión diferencial de genes (Gutiérrez-Correa, 2003). Las biopelículas son sistemas formados por microorganismos adheridos a superficies.

Las biopelículas bacterianas han sido ampliamente estudiadas desde el punto de vista estructural y fisiológico, y son consideradas estructuras complejas y heterogéneas; en las cuales las células adheridas difieren radicalmente de las planctónicas y muestran mayor resistencia a compuestos biocidas, surfactantes y al desecado (O'Toole et al., 2000; Blenkinsopp, 1991).

A diferencia de las biopelículas bacterianas, las biopelículas fúngicas han recibido menor atención, aunque recientemente están cobrando mayor relevancia en medicina por ser causantes de infecciones relacionadas con implantes, principalmente el causado por Candida (Chandra et al., 2001; O'Toole et al., 2000).

El presente trabajo realiza un análisis estructural de las biopelículas de Aspergillus niger desarrolladas sobre tela de poliéster, a partir de microfotografías electrónicas, en un intento por determinar el patrón morfológico relacionado al comportamiento fisiológico particularmente asociado a la producción de enzimas celulolíticas.

\section{Materiales y métodos}

\section{Microorganismo}

En esta investigación se utilizó la cepa Aspergillus niger ATCC 10864, productora de celulasa y hemicelulasas, la cual fue mantenida en Agar Papa Dextrosa (APD).

\section{Formación de biopelículas}

Para la formación de biopelículas se inoculó una suspensión de $10^{6}$ esporas/mL $(3 \% \mathrm{v} / \mathrm{v})$ en matraces que contenían $30 \mathrm{ml}$ de medio de crecimiento (Duff, 1988) y un cuadrado de tela de poliéster de $2 \mathrm{~cm}$ de lado (Villena et al., 2001). Los cultivos crecieron en agitación (175 
rpm) a $28{ }^{\circ} \mathrm{C}$ durante 120 horas. Se obtuvieron biopelículas de 24, 48, 72, 96 y 120 horas de crecimiento, con 4 muestras para cada tiempo. Dos muestras fueron secadas para determinar el peso de biomasa adsorbida y biomasa total. Las otras biopelículas fueron lavadas en buffer citrato $50 \mathrm{mM}$ antes de ser sometidas al tratamiento de fijación para microscopía electrónica.

\section{Determinación de biomasa de las biopelículas}

Para determinar la biomasa adsorbida en las biopelículas, se hicieron tres lavados con buffer citrato en agitación (200 rpm) durante 10 minutos con el propósito de remover la biomasa débilmente adsorbida. Luego, la biopelícula fue secada a $105{ }^{\circ} \mathrm{C}$ durante 24 horas y se determinó el peso seco de biomasa, por diferencia de peso con el soporte. $\mathrm{La}$ biomasa remanente en el medio de cultivo y la biomasa desprendida en los lavados fue filtrada y también se secó en las mismas condiciones para determinar el peso seco. La biomasa total resultó de la suma de la biomasa adsorbida y la biomasa libre.

Tratamiento de biopelículas para microfotografías electrónicas

El tratamiento de las biopelículas para la toma de microfotografías consistió en: 1) fijación de las muestras en una solución de glutaraldehído al $3 \%$ en buffer cacodilato $0,1 \mathrm{M}$ $(\mathrm{pH} 7,4)$ durante 72 horas a $4{ }^{\circ} \mathrm{C}$ para conservar sus características estructurales y morfológicas; 2) osmoficación, las biopelículas se colocaron en una solución de tetraóxido de osmio al $2 \%$ en buffer cacodilato; 3 ) deshidratación con una batería de etanol al 30, 50, $70,80,95$, y $100 \%$; 4) secado a Punto Crítico para reemplazar el etanol por $\mathrm{CO}_{2}$ que luego se evapora a alta temperatura, lo cual permite mantener intacta la estructura de la biopelícula; 5) bañado superficial de oro en un cobertor iónico durante un tiempo promedio de $50 \mathrm{se}$ gundos (Brown, 1979). Terminado el tratamiento las muestras fueron fotografiadas con un Microscopio Electrónico de Barrido Philips modelo 515.

\section{Inóculo}

Aspergillus niger se mantuvo en placas con agar papa dextrosa (APD) durante cinco días hasta la esporulación. En condiciones estériles se cosecharon las esporas con solución de Tween al $0.1 \%$, obteniéndose una suspensión con $10^{6}$ esporas $/ \mathrm{mL}$. Para los sistemas de fermentación con biopelícula y fermentación sumergida con micelio libre se utilizó una proporción de inóculo de 3\%.

\section{Producción de celulasas con biopelículas}

Se realizó una fermentación de 72 horas para la obtención de enzimas celulolíticas en sistemas de cultivo con biopelículas y también con sistemas de micelio libre como controles del experimento. Las biopelículas se obtuvieron inoculando una suspensión de esporas directamente sobre la tela en los matraces de cultivo. Inmediatamente, la tela fue lavada con buffer citrato $50 \mathrm{mM} \mathrm{pH} \mathrm{4,8} \mathrm{(para} \mathrm{retirar} \mathrm{las}$ esporas no adheridas) y luego se transfirió a otro matraz para iniciar la fermentación.

Para ambos casos, la composición del medio de fermentación fue $\mathrm{KH}_{2} \mathrm{PO}_{4}, 2 \mathrm{~g} / \mathrm{L}$; $\mathrm{CaCl}_{2} .2 \mathrm{H}_{2} 0,0,3 \mathrm{~g} / \mathrm{L}, \mathrm{MgSO}_{4} .7 \mathrm{H}_{2} \mathrm{O}, 0,3 \mathrm{~g} / \mathrm{L}$, urea, $0,3 \mathrm{~g} / \mathrm{L}$, $\left(\mathrm{NH}_{2} \mathrm{SO}_{4}\right), 1,4 \mathrm{~g} / \mathrm{L}$, Tween 80,2 $\mathrm{ml}$. $\mathrm{FeSO}_{4} \cdot 7 \mathrm{H}_{2} \mathrm{O}, 5 \mathrm{mg} / \mathrm{L} ; \mathrm{MnSO}_{4} .2 \mathrm{H}_{2} \mathrm{O}, 1,6$ $\mathrm{mg} / \mathrm{L} ; \mathrm{ZnSO}_{4} .7 \mathrm{H}_{2} \mathrm{O}, 1,4 \mathrm{mg} / \mathrm{L} ; \mathrm{CoCl}_{2} .{ }_{6} \mathrm{H}_{2} \mathrm{O}, 2$ $\mathrm{mg} / \mathrm{L}$; Lactosa $10 \mathrm{~g} / \mathrm{L}$; $\mathrm{pH}$ final del medio 5,5 (Duff, 1988).

Los matraces con $30 \mathrm{~mL}$ de medio de producción fueron incubados, después de la inoculación a $28^{\circ} \mathrm{C}$ con una agitación de $175 \mathrm{rpm}$ durante 3 días. Cada 24 horas se utilizaron dos cultivospara determinar la actividad enzimática de celulasas y el consumo de lactosa.

\section{Determinación de la lactosa residual}

La determinación de lactosa residual en el medio de cultivo se realizó de acuerdo al método de Miller utilizando ácido dinitrosalicílico (DNS) (Miller, 1959).

\section{Determinación de la actividad de celulasa}




\section{total}

La actividad de celulasa total fue determinada a partir del medio de cultivo por el ensayo de actividad sobre papel de filtro, de acuerdo al método descrito por Mandels (Mandels, 1975; Ghose,1987). Una Unidad Internacional de enzima (UI) se define como la cantidad de enzima que libera 1 micromol de glucosa por minuto.

\section{Resultados y discusión}

En general la formación de biopelículas sigue un proceso en el cual puede distinguirse, tres fases que incluyen la adhesión inicial de células, el desarrollo y crecimiento y la maduración. Aunque esta afirmación es válida principalmente para bacterias y levaduras de importancia clínica como Candida, también puede aplicarse a las biopelículas de hongos filamentosos a pesar de no haber sido descritas en detalle. Sin embargo, por la forma de crecimiento de estos microorganismos sobre sustratos naturales puede inferirse que presentan una tendencia a la formación de biopelículas, las cuales pueden desarrollarse aun sobre materiales sintéticos.

La formación de biopelículas por los hongos es un proceso complejo que se inicia con la adhesión de esporas a una superficie, la cual está influenciada por factores físicos, químicos y medioambientales. Tanto los microorganismos como las superficies tienen un potencial negativo que generarían repulsión electrostática, la cual podría contrarrestarse con fuerzas de atracción temporales tipo Van der Waals o atracción hidrofóbica (Jones, 1994). Cuando la espora llega a la superficie se adhiere para iniciar la germinación, las superficies naturales son comúnmente hidrofóbicas, y la adhesión y germinación de las esporas está determinada por la presencia de proteínas hidrofóbicas de pared denominadas hidrofobinas. Las hidrofobinas son pequeñas proteínas, moderadamente hidrofóbicas, caracterizadas por conservar ocho residuos de cisteína y patrones hidropáticos típicos; son producidas por especies de ascomicetos, basidomicetos y zigomicetos y desempeñan diversas funciones en el crecimiento y desarro1lo. Entre esas funciones está la adsorción pasiva de esporas o hifas a superficies hidrofóbicas (que producen señales morfogenéticas) y la formación de estructuras hidrofóbicas aéreas como micelio y cuerpos fructíferos (Clement et al., 1994; Lugones et al., 1998; Stringer y Timberlake, 1995; Wosten y Willey, 2000). La propiedad característica de las hidrofobinas es la formación de una membrana anfipática en contacto con una interfase hidrofílica-hidrofóbica lo cual permite cambiar la naturaleza de la superficie. Aspergillus niger produce hidrofobinas intracelulares en esporas y micelio (Askolin et al., 2001). La Figura 1A muestra la adsorción de esporas de Aspergillus en las fibras de poliéster con un tiempo de contacto mínimo (10 minutos). Esto sugiere un carácter fuertemente hidrofóbico de las esporas que han permanecido adheridas a las fibras de poliéster aún despues del tratamiento de fijación. La adsorción de esporas también puede ser mediada por producción de mucílagos adhesivos que determinan la adsorción activa de hongos. Este segundo mecanismo parece estar ausente en la adhesión de esporas de Aspergillus.

El mecanismo de adhesión celular para formar biopelículas bacterianas es más conocido y consiste en una atracción inicial de las células a las superficies mediada por fuerzas electrostáticas y seguida de la producción de expolisacáridos que promueven la adhesión irreversible en la etapa de maduración de la biopelícula (Blenkinsopp, 1991; Ghigo, 2003). En el caso de biopelículas de Candida, ésta empieza a partir de la adhesión de células levaduriformes en la superficie basal, mientras que la capa superior contiene formas hifales, siendo al parecer las células levaduriformes las que determinan la fuerza de adhesión, ya que una biopelícula que solamente tenía morfología hifal mostró tener biomasa débilmente adherida (Ghigo, 2003). Otro modelo de biopelícula de Candida con- 


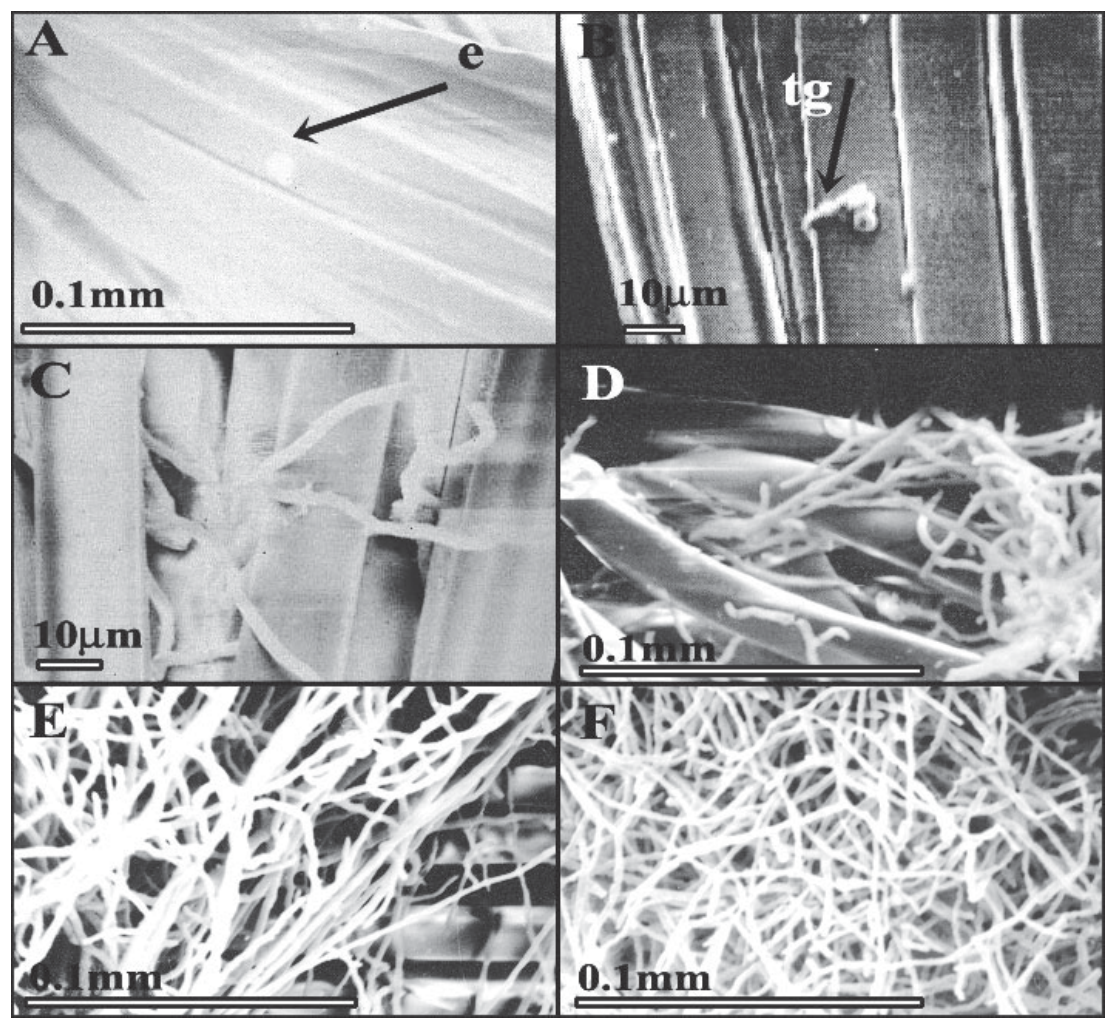

Figura 1. Formación de la biopelícula de Aspergillus niger por crecimiento sobre poliéster: (A) 0 horas, (B) 4 horas, (c) 10 horas, (D) 18 horas, (E) 24 horas; (F) 120 horas de crecimiento.

siste en blastosporas adheridas a la capa basal y células hifales embebidas en material extracelular. Aunque Sacharomyces cerevisae también es capaz de adherirse a soportes sintéticos, no genera biopelículas maduras.

En el caso de Aspergillus el desarrollo de la biopelícula se inicia con la germinación de esporas entre las 4 y 8 horas después de la adhesión. La Figura 1B corresponde a las 8 horas de crecimiento de biopelículas, y en ella se puede apreciar la formación del tubo germinativo. El carácter hidrofóbico del poliéster utilizado como soporte (Villena et al., 2001) facilita el crecimiento de las hifas adsorbidas al soporte, como se aprecia en la Figura $1 \mathrm{C}$ a las 10 horas de crecimiento.

En forma similar a la dinámica de formación de biopelículas bacterianas en las que hay una formación inicial de microcolonias, a partir de las cuales se generan nuevas células o se atraen células planctónicas a la biopelículas (Blenkinsopp, 1991), aparentemente hacia las 18 horas de crecimiento pueden apreciarse en la Figura 1D microcolonias de Aspergillus, cuyas hifas se elongarán posteriormente para iniciar la colonización de la superficie en las siguientes horas de crecimiento (Fig. 1E). Es importante resaltar que durante el crecimiento de la colonia, las hifas crecen manteniendo una distancia entre ellas (Fig. 6); este fenómeno conocido como exclusión hifal evita la compactación del micelio a medida que la densidad de la película aumenta (Prosser, 1994). Se puede afirmar que la adhesión inicial de células o esporas, determinará la estructura y estabilidad de la biopelícula. En este sentido, la hidrofobicidad de las esporas de Aspergillus le confiere ventajas únicas para el desarrollo de biopelículas.

En la fase de maduración, las biopelículas de Aspergillus difieren de las biopelículas bacterianas. Estas últimas se caracterizan por tener una estructura completamente heterogénea en la cual pueden distinguirse células, exopolisacáridos y células inviables. A medida que esta heterogeneidad se incrementa con el crecimiento de la biopelícula 

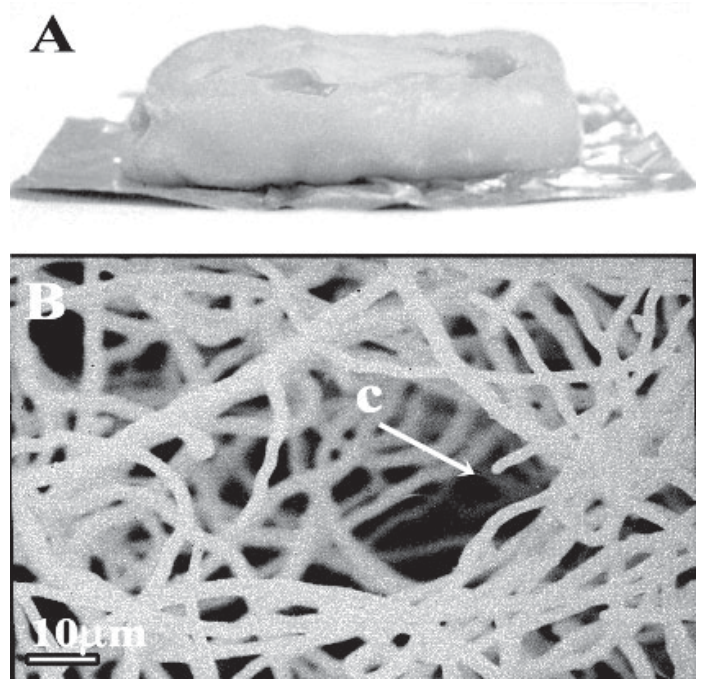

Figura 2. Densidad de la biopelícula de Aspergillus niger a las 120 horas de crecimiento $(A)$, cuya microfotografía $(B)$ muestra una estructura interna de canales.

se establecen microgradientes químicos, microambientes aeróbicos y anaeróbicos, gradientes de $\mathrm{pH}$. Sin embargo, pese a la densidad de la película, es posible el flujo de agua al interior de la película. Esto se deduce de la gran capacidad de hidratación que se ha encontrado en las películas bacterianas y que están directamente relacionadas a la presencia de canales internos, organizados durante el crecimiento celular, los cuales aseguran el movimiento interno de fluidos (de Beer y Stoodley, 1995; Stoodley et al., 1994; Ghigo, 2003). Ningún patrón morfológico similar de canales internos ha sido reportado para las biopelículas de Candida (Chandra et al., 2000). Comparativamente, las biopelículas de Aspergillus no son estructuralmente heterogéneas, la Figura $1 \mathrm{~F}$ evidencia un incremento de la densidad celular desde las 72 horas y aparentemente no presenta una matriz extracelular. Sin embargo, en forma similar a las biopelículas bacterianas, las desarrolladas por Aspergillus muestran una gran capacidad de retención de agua, y esto puede evidenciarse en el volumen alcanzado por la biopelícula las 96 horas de crecimiento (Fig. 2A). La retención de agua dentro de la biopelícula de Aspergillus también refleja una arquitectura interna de canales, los cuales son evidentes en la Figura 2B, permitiendo el flujo al interior de la biopelícula. Esto fue comprobarse durante la fermentación, en la cual se determinó que la concentración de lactosa en el medio de cultivo coincidía con la concentración del medio retenido dentro de la biopelícula (datos no mostrados).

La Figura 3 muestra la cinética de conversión de lactosa de la biopelícula y el cultivo en fermentación sumergida. En ella se puede apreciar que la conversión inicial de lactosa es menor en la biopelícula durante la fase de adhesión y crecimiento respecto a la del micelio libre. Sin embargo durante la maduración la conversión es mayor, lo cual sugiere que no existen barreras difusionales dentro de la película, pese a la densidad alcanzada por ésta.

La arquitectura dinámica interna de las biopelículas bacterianas ha sido estudiada in vivo utilizando microscopía láser confocal, con lo cual se ha demostrado el flujo de agua a través de los canales internos de la biopelícula; sin embargo no existen reportes similares para la arquitectura de biopelículas de hongos filamentosos, por lo cual las microfotografías electrónicas mostradas constituyen una primera aproximación hacia el estudio estructural de biopelículas de hongos filamentosos, parti-

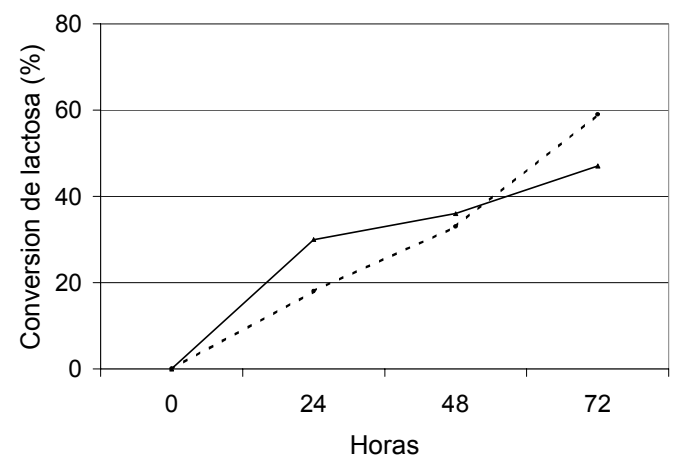

Figura 3. Conversión de Lactosa durante el curso de la fermentación para la producción de celulasas con Aspergillus niger mediante biopelículas (línea punteada) y en crecimiento libre (línea continua). 


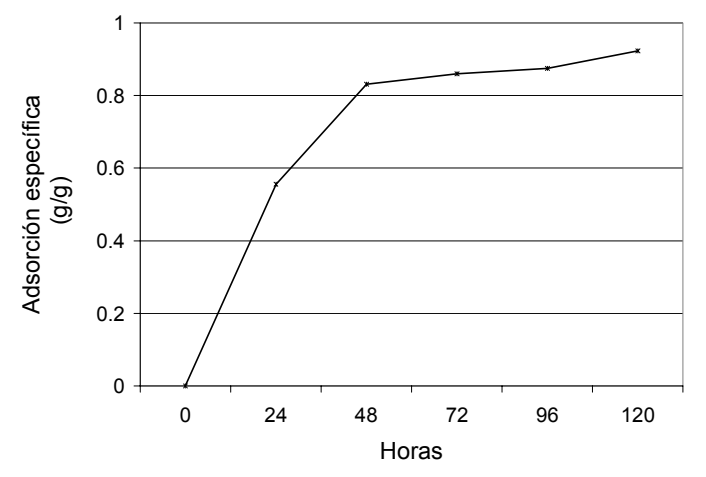

Figura 4. Adsorción Específica de Biomasa de Aspergillus niger en crecimiento sobre poliéster.

cularmente aquellos de interés industrial.

La dinámica de formación de biopelículas de Aspergillus está correlacionada con el comportamiento de la biomasa durante el crecimiento de la biopelícula. La Figura 4 muestra la adsorción específica (peso de biomasa adsorbida/ peso de biomasa total) de Aspergillus cuando crece adherido a tela de poliéster. Durante las primeras 24 horas, correspondientes a la adhesión y el crecimiento inicial de la biopelícula, la adsorción de biomasa corresponde al $60 \%$ de la biomasa total. La fase de desarrollo y maduración se traduce en un incremento de la adsorción específica desde las 48 horas hasta las 120 horas, tiempo en el cual el $90 \%$ de la biomasa está adherida. Aparentemente, la desorción de biomasa no es significativa.

Además del aspecto estructural, las biopelículas son importantes porque promueven un cambio fisiológico en los microorganismos. En bacterias, después de la adhesión se inicia una adaptación en respuesta a esta nueva condición de crecimiento, la cual se refleja en el incremento en la síntesis de exopolisacáridos y el desarrollo de una resistencia a antibióticos. Aparentemente, los exopolisacáridos interactúan físicamente con los antibióticos con lo cual se genera la resistencia de la biopelícula (Chandra et al., 2000). También pueden desarrollar resistencia a la radiación UV, incrementar la tasa de intercambio genético, cambiar sus propiedades biodegradativas e incrementar la producción de metabolitos secundarios (O’ Toole et al., 2000).

En la formación de biopelículas de Candida y Saccharomyces, desde la adhesión a superficies sintéticas (material para prótesis e implantes) ocurren cambios en la expresión genética durante la transición del estado planctónico al crecimiento en biopelícula, habiendo una mayor expresión adicional de genes en esta última condición. En las biopelículas de Candida ocurre una progresión de la resistencia a antifúngicos asociada a un incremento de la actividad metabólica de las biopelículas y al tiempo de desarrollo (Chandra et al., 2000).

Los hongos filamentosos también muestran comportamientos fisiológicos distintos asociados al crecimiento sobre superficies derivados de una expresión diferencial de genes (Gutiérrez-Correa, 2003). Se ha probado la expresión diferencial de celulasas de Trichoderma y Aspergillus en fermentación en sustrato sólido (FSS) respecto a fermentación sumergida (FS) (Considine et al., 1986). Asimismo, Phanaerochaete chrysosporium produce patrones de transcripción de celobiohidrolasa distintos cuando crece sobre astillas de madera respecto del crecimiento en cultivos sumergidos con medios definidos de celulosa o glucosa (Vallim et al., 1998). Además, Aspergillus oryzae expresa un tipo de glucoamilasa en FSS pero no en FS (Hata et al., 1998).

De otro lado, las biopelículas desarrolladas sobre soportes inertes y sintéticos muestran generalmente una producción mayor de metabolitos y enzimas respecto a los cultivos en fermentación sumergida. Aspergillus niger produjo un mayor nivel de ácido cítrico en un reactor de discos rotatorios (Anderson et al. 1980) mientras que cuando Aspergillus oryzae creció adherido hubo un incremento de 50 veces en la producción de ácido kójico respecto a cultivos sumergidos en lote (Ogawa et al., 1995). Sakurai et al. (1989) utilizaron fibras de poliéster como soporte de inmovilización de Aspergillus niger para la producción de ácido glucónico durante 14 lotes a una 
tasa constante durante un período aproximado de 1000 horas. La producción de otros ácidos, como el ácido itacónico y ácido giberélico, también ha sido probada con éxito utilizando biopelículas de Aspergillus terreus desarrolladas sobre soportes de acero inoxidable y celita, y Fusarium moniliforme adsorbido a vidrio (Vassilev y Vassileva, 1992).

Los reportes en producción de enzimas también señalan la mayor productividad de biopelículas. Phanerochaete chrysosporium inmovilizado sobre esponja de poliuretano produjo niveles altos de lignina-peroxidasa y se mantuvo en 8 lotes repetidos (Capdevila et al., 1989). Haapala et al. (1996) estudiaron el efecto de la fuente de nitrógeno en la producción de endoglucanasa y xilanasa con Trichoderma reese $i$ adsorbido sobre nailon en medios que contienen lactosa, celulosa y soforosa. En todos los medios estudiados, la actividad enzimática del cultivo inmovilizado fue mayor a la del cultivo con micelio libre; y la adición de fuentes orgánicas de nitrógeno, como extracto de levadura y peptona, incrementaron la producción de enzimas. Webb et al. (1986) llevaron a cabo la producción continua de celulasa con Trichoderma viride inmovilizado en esferas de acero, en un medio que contiene glucosa como fuente de carbono; la productividad específica de celulasa de las biopelículas fue 3 veces mayor que la de las células no inmovilizadas. Zhaoxin

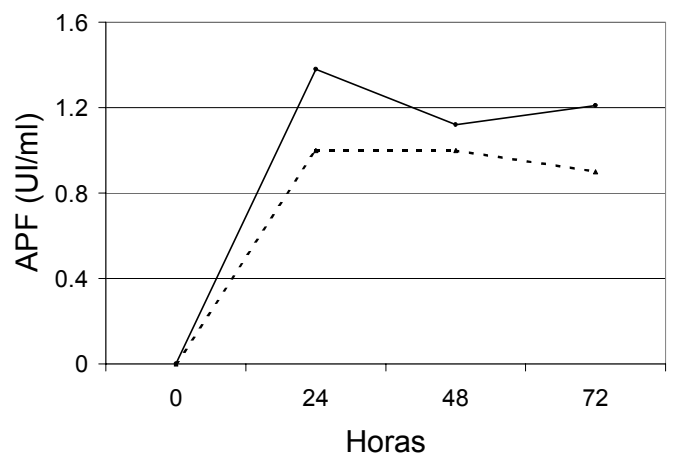

Figura 5. Comparación de la actividad celulolítica de biopelículas de Aspergillus niger (línea continua) respecto a fermentación sumergida(línea punteada). y Kumamura (1994) probaron un soporte de inmovilización consistente en papel recubierto de trimetilpropano triacrilato (monómero) polimerizado con radiación, y obtuvieron una superficie hidrofóbica favorable a la adsorción y crecimiento de $T$. reesei para la producción de celulasa. La productividad de celulasas de las células inmovilizadas fue superior a la de las células sin soporte.

La Figura 5 muestra la cinética de producción de celulasas en la que se observa que la actividad celulolítica de las biopelículas es superior durante el curso de la fermentación, y la mayor actividad enzimática ocurre a las 24 horas. Se ha probado la presencia de celulasas en la pared celular de conidias de Trichoderma, las cuales son esenciales para el crecimiento sobre celulosa ya que liberan inductores naturales para la producción continua de estas enzimas (Seiboth et al., 1999). Probablemente hay un mecanismo similar en Aspergillus que explique este pico inicial de actividad. Aunque generalmente el incremento en la actividad metabólica se ha relacionado con la densidad celular, los resultados obtenidos en la producción de celulasas sugieren que la adsorción de microorganismos a superficies genera una respuesta fisiológica distinta reflejada en la mayor producción de celulasas de Trichoderma y Aspergillus (Villena et al., 2001).

La productividad de celulasas de biopelículas de Aspergillus fue 55\% más alta que la del mismo cultivo en fermentación sumergida, tal como se evidencia en la Figura 6, con ello se demuestra el potencial de las biopelículas de hongos para la producción de enzimas.

\section{Conclusiones}

Las biopelículas son sistemas estructuralmente complejos y de características fisiológicas especiales asociadas a una mayor actividad metabólica y resistencia a compuestos tóxicos. Los hongos filamentosos están naturalmente adaptados al crecimiento sobre su- 


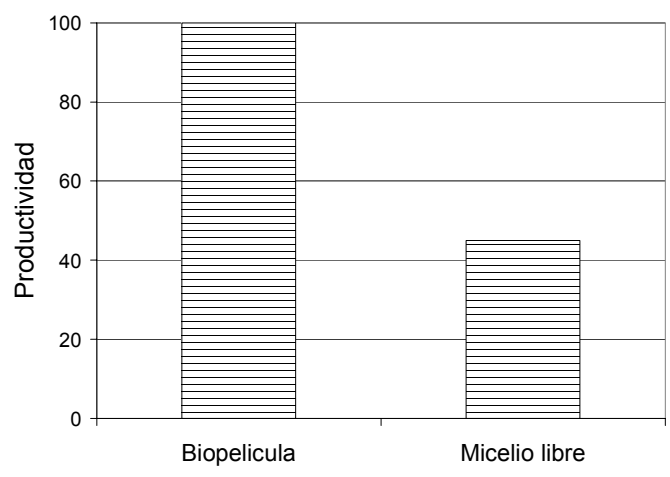

Figura 6. Comparación de la productividad volumétrica máxima de celulasas producidas por Aspergillus niger por crecimiento en biopelículas y como micelio libre.

perficies y, por lo tanto, forman biopelículas. Esta forma de crecimiento, al igual que en bacterias y levaduras, supone una expresión diferencial de genes reflejada en una mayor producción de enzimas o metabolitos.

Los resultados obtenidos en este trabajo muestran que las biopelículas de Aspergillus niger se caracterizan por la presencia de canales internos que permiten el flujo interno y, por otro lado, producen una mayor cantidad de celulasa en comparación al cultivo con micelio libre. Esta primera aproximación busca enfocar la investigación hacia este aspecto de crecimiento y producción en hongos filamentosos.

El mejor entendimiento de las biopelículas de hongos filamentosos utilizando técnicas moleculares y visualización microscópica directa contribuirán grandemente al desarrollo de procesos productivos basados en las ventajas fisiológicas de las biopelículas de hongos de interés industrial.

\section{Agradecimientos}

Los autores expresan su agradecimiento al Dr. Luis Salazar y al Blgo. Octavio Zegarra, del Centro Internacional de la Papa por su colaboración en la toma de microfotografías electrónicas.

\section{Literatura citada}

Anderson, J. G. 1983. Immobilized cell and film reactor systems for Filamentous fungi. The
Filamentous Fungi, Volume 4 Chapter 6 (J. E. Smith, D.R. Berry, B. Kristiansen, eds.). E. Arnold, London.

Anderson, J. G.; J. A. Blain, M. Divers, J. R. Todd. 1980. Use of the disc fermenter to examine production of citric acid by Aspergillus niger. Biotechnology Letters 2: 99-104.

Askolin, S.; T. Nakari-Setälä, M. Tenkanen. 2001. Overproduction, purification, and caracterization of the Trichoderma reesei hydrophobin HFBI. Applied Microbiology and Biotechnology. 57:124-130.

Jones, J. B. G. (1994). Fungal adhesion. Mycological Research 98: 961-981.

Chandra, J.; D. M. Jun, P. K. Mukherjee, L. L. Hoyer, T. McCormick, M. A. Ghannoum. 2001. Biofilm Formation by the Fungal Pathogen Candida albicans: Development, Architecture and Drug Resistance. Journal of Bacteriology 183: 5385-5394.

Blenkinsopp, S. A and J. W. Costerton. 1991. Understanding Bacterial Biofilms. Trends in Biotechnology 9: 138-143.

Brown, F. M.; G. G. Brotzman. 1979. Phytopathogenic Fungi: A Scanning Electron Steroscopic Survey. Board of curators. University of Missouri. USA.

Capdevila, C.; G. Corrieu and M. Asther. 1989. A feedharvest culturing method to improve lignin peroxidase production by Phanerochaete chrysosporium INA-12 immobilized on polyurethane foam. Journal of Fermentation and Bioengineering 68:60-63.

Clement, J.; R. Porter, T. Butt, A. Beckatt. 1994. The role of hidrofobicity in attachment of uredinospores and sporelings of Uromyces viciae-fabae. Mycological Research 98:12171228

Considine, P.; R. Mehra, T. Hackett, A. O'Rorke, F. Comerford, M. Coughlan. 1986. Upgrading the value of agricultural residual. Annals of the New York Academy of Sciences 469:304-311.

de Beer, D. and P. Stoodley. 1995. Relation between the structure of an aerobic biofilm and transport phenomena. Water Science Technology 32: 1118.

de Vries, R. P. and J. Visser. 2001. Aspergillus Enzyme Involved In Degradation Of Plant Cell Wall Polysaccharides. Microbiology and Molecular Biology Reviews 65:497-522.

Duff, J. 1988. Use of surface-immobilized Trichoderma in batch and fed-batch fermentation. Biotechnology and Bioengineering 31: 345348.

Ghigo, J. M. 2003. Are There Biofilm-Specific Physiological Pathways beyond a Reasonable Doubt? Research in Microbiology 154: 1-8. 
Ghose; T. 1987. Measurement of cellulolitic activities. Pure and Applied Chemistry 59: 257-268.

Gutiérrez-Correa, M. 2003. Opinion on Surface Adhesion Fermentation. Agriculture Food Research. New1 (en prensa).

Haapala, R.; E. Parkinnen,P. Suominen,S. Linko. 1996. Production of endo-1,4 â glucanase and xylanase with nylon-web immobilized and free Trichoderma reesei. Enzyme and Microbial Technology 18:495-501.

Hata, Y.; H. Ishida, E. Ichikawa, A. Kawato, K. Suginami, S. Imayasu. 1998. Nucleotide sequence of an altenative gluamylase-encoding gene ( glaB) expressed in solid-state culture of Asperfillus oryzae. Gene 207:127-134.

Lugones, L.; H. Wostwn, G. Wessels. 1998. A hydrphobin (ABH·) specifically secreted by vegetatively growing hyphae of Agaricus bisporus (common white button mushroom) Microbiology. 144:2345-2353.

Mandels, M.; D. Stemberg, R. Andreotti. 1975. Growth of cellulase production by Trichoderma. En Proceedings of symposium on the Enzimatic Hydrolisis of Cellulose eds. M. Bailey, T. M. Enari \& Linko. pp 81-109. Helsinki. SITRA

Miller, G. 1959. Use of Dinitrosalicylic acid reagent for determination of reducing sugar. Analytical Chemistry 31:426-428.

Ogawa, A.; Y. Morita, T. Sakiyama, K. Nakanishi. 1995. Production of Kojic Acid from Aspergillus oryzae var. oryzae by membrane-surface liquid culture. Biotechnology Techniques 9: 153-156.

O’Toole, G.; H. B. Kaplay, R. Kolter. 2000. Biofilm Formation as Microbial Development. Annual Reviews in Microbiology 54:49-79.

Prosser, J. I. 1994. Kinetics of filamentous growth and barnaching. En "The growing Fungus", p. 301318. (Neil A. R. Gow \& G. M. Gadd, eds.). Chapman \&Hall, London.

Sakurai, H.; W. Lee, S. Sato, S. Mukataka,J. Takahashi. 1989. Gluconic acid production at high concentrations by Aspergillus niger immobilized on a nonwoven fabric. Journal of Fermentation and Biotechnology 67: 404-409.

Seiboth, B.; R. L. Hakola, P. L. Mach, Suominen and C.P. Kubicek. (1997) Role of Four Major Cellulases in Triggering of Cellulase Gene Expression by Cellulose in Trichoderma reesei. Journal of Bacteriology. 179:5318-5320

Stringer, M. and W. Timberlake. 1995. dew A encodes a fungal hydrophobin component of the Aspergillus spore wall. Molecular Microbiology 16: 33-44.

Stoodley, P. D. de Beer, Z. Lewandowski. 1994. Liquid Flow in Biofilms Systems. Applied and Environmental Micorbiology 60: 2711-2716.

Vallim, M.; B. H. J. Janse, J. Gaskell, A. A. PizziraniKleiner, D. Cullen. 1998. Phanerochaete chrysosporium Cellobiohydrolase and cellobiose dehydrogenase transcripts in wood. Applied and Environmental Microbiology 98: 1924-1928.

Vassilev, N. and M. Vassileva. 1992. Production of organic acids by immobilized filamentous fungi. Mycological. Research 96: 563-570.

Villena, G.; P. Moreno, M. Gutiérrez-Correa. 2001. Cellulase production by fungal biofilms on polyester cloth. Agro-food-Industry Hi-Tech, 12 (Iss 1): 32-35.

Webb, C.; H. Fukuda, B. Atkinson. 1986. The production of cellulase in a spouted bed fermentor using cells immobilized in biomass support particles. Biotechnology and Bioengineering 28: 41-50

Wosten, H. and J. Willey. 2000. Surface active proteins enable microbial aerial hyphae to grow in the air. Microbiology 146: 767-773.

Zhao Xin, L.; M. Kumamura. 1994. Characteristics of filamentous cells immobilized with ionichydrophobic polymers prepared by a radiation polymerization method. Process Biochemistry 29: 651-656. 